\title{
DEVELOPMENT OF A PORTABLE HOUSEHOLD WATER DEVICE FOR IMPROVING DRINKING WATER QUALITY IN NIGERIA
}

\author{
$1,{ }^{*}$ AKINBOMI, J.G., ${ }^{2}$ ODIKA, I.I. \\ ${ }^{1}$ Department of Chemical Engineering, Lagos State University, Epe Campus, \\ julius.akinbomi@lasu.edu.ng \\ ${ }^{2}$ Centre for Environmental Studies and Sustainable Development, Lagos State University, Ojo Campus, \\ 2́fabbieify@yahoo.com \\ *Corresponding author
}

Received:12 ${ }^{\text {th }}$ December 2019

Accepted: $14^{\text {th }}$ May 2020

Published: $20^{\text {th }}$ September 2020

https://doi.org/10.47545/etrj.2020.5.2.065

\begin{abstract}
Pipe borne water supplied to Nigerian households may not always meet the accepted drinking water quality standards due to possible water pipe damage. The objective of this study was, therefore, to develop a portable water filter device for improving household drinking water quality. Five litres of representative tap water samples collected from Lagos State University Staff quarters were passed through the developed device. The experimental variables investigated for data acquisition were aeration period of untreated tap water; device backwashing operation cycles and retention times of tap water in the filter device. The results of the analyses of water samples for the various values of the experimental variables showed that the range values of water parameters between the treated and untreated tap water samples were $0.04-0.05,0.02-0.03,0.04-0.12,0.3-0.4,125-137,10-20,3-10 \mathrm{mg} / \mathrm{L}$ for barium, chromium, iron, $\mathrm{pH}$, Total Dissolved Solids, hardness and chloride, respectively. Although the developed device helped in improving the quality of the tap water; the p-values for the different experimental variables were greater than $\alpha$-level of 0.05 indicating the non-significance of using the developed water device. Consequently, future study will consider other experimental variables that will justify the significance of using the developed device.
\end{abstract}

Keywords: Households, Filter device, Tap water, Improvement, Water quality

\section{INTRODUCTION}

The necessity of potable water for human survival cannot be understated. Many people, especially in the developing countries like Nigeria have limited access to constant supply of potable water despite the existence of water distribution pipeline network in most Nigerian cities [1-3]. The non-functional state of the water distribution system has been attributed to factors including poor maintenance culture with consequent breakdowns and failing infrastructure, erratic power supply, among others. Many of the water pipe networks are comprised of old, rusty, and broken pipes that are laid in open gutters and dirty water. Irregular supply of power has impaired the smooth running of the electrical equipment for the water distribution. Due to acute problems of power supply, water agencies spend resources on diesel to power generators. As such, majority of Lagos residents are not connected to pipe borne water and, therefore, depend on other sources of water including water tankers, boreholes and wells. This in turn has its associated challenges including contamination from septic tanks or drains, costs of water delivery, as well as, impact on the groundwater levels in the state. Even in Nigerian households with supply of pipe borne water, the water may not always meet the accepted drinking water quality standards due to possible water pipe damage that may occur from unmaintained or corroded water pipes. Water supplied to people through unmaintained water distributed systems is often contaminated, thereby, affecting the quality of water that flows through the taps and causing damage to human health [4]. In fact, most deaths worldwide are often attributed to contaminated water [5]. It is therefore necessary to develop a portable household water device that can be used for the treatment of water suspected to have been contaminated. There is a paucity of researches on design of a portable household drinking water filter device for improving pipe borne water quality. Although many studies have been carried out globally regarding the development of portable water purification device [6,7], relatively little is known about the development of the device for post-treatment of pipe borne water supplied to Nigerian households. Therefore, the objective of this study was to develop a portable water treatment device for improving household drinking water quality. The effectiveness of designed household water filter device would be assessed. 
This study will be of great significance as it will add to the already existing literatures. The portable water filter device would enable people to be less dependent on the government for the provision of healthy water. The device would also develop the capacity of people regarding the treatment of water for safe consumption.

\section{MATERIALS AND METHODS}

Activities related to the study include research design, sample and sampling technique, instrumentation, validity of the instrument, reliability of the instrument, procedure for data collection, and procedure for data analysis. The study area was on the design of a household water treatment device for improving pipe borne water quality with the focus on the effectiveness of the house hold water treatment device that was developed. The source of the pipe borne water used in the preliminary study was delimited to only pipe borne water in Lagos State University Staff Quarters, Epe campus, Lagos State, Nigeria. Other sources of pipe borne water will be used in future studies. Representative pipe borne water samples were collected by washing and rinsing the sample bottles with distilled water, steam sterilizing of the bottles at $120^{\circ} \mathrm{C}$ for 20 minutes, flame sterilizing of tap spout/nozzle, opening of the tap to allow the water to flow for 1 to 2 minutes at normal rate before collecting the representative samples. The collected sample was closed and kept in a cool place [8].

The experimental materials included weighing balance, funnel, measuring cylinder, calibrated bucket, portable household water filter device and its filter beds. The filter beds comprised of $4 \mathrm{~mm}$ gravel, $3 \mathrm{~mm}$ gravel, $2 \mathrm{~mm}$ sand, activated carbon, green sand, birm, chlorine and caustic soda. The $2 \mathrm{~mm}$ sand filter, $3 \mathrm{~mm}$ gravel and $4 \mathrm{~mm}$ gravel were responsible for filtration and removal of debris from water. The activated carbon removed water odour and tastes; green sand and birm helped in the removal of some of the compounds in water while chlorine helped to kill microorganisms in water and also act as a preservative for the water when stored. Caustic soda helped to boost the $\mathrm{pH}$ since the water samples are acidic in nature. The components of media/filter bed, as well as other chemicals for water treatment were stored in separate containers prior to the experimental process. The portable household water filter device developed was made of two components; the stainless filter component and the cartridge filter component (Figure 1a). The dimensions of the portable household water filter device are shown in Figure 1b. The operation of the water filter device was based on gravitational flow process, and as such, electrical power was not required for the operation of the water filter device.

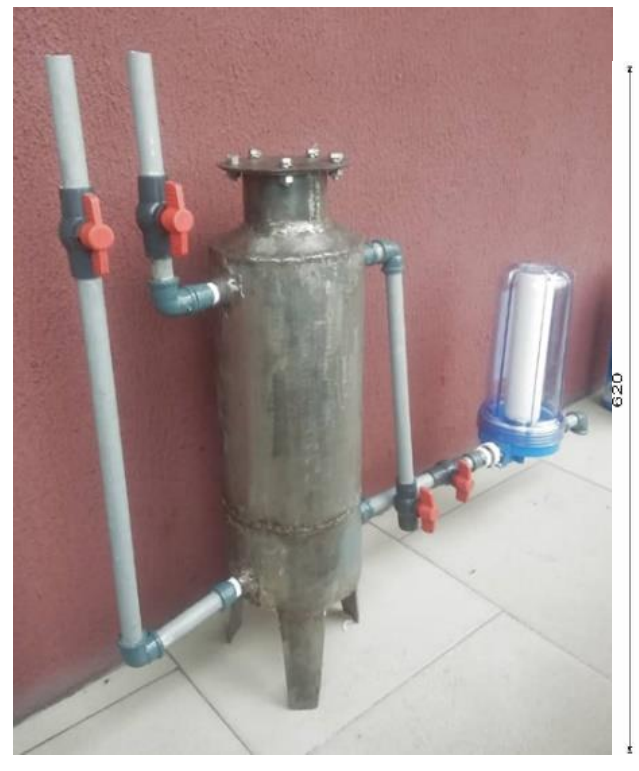

a

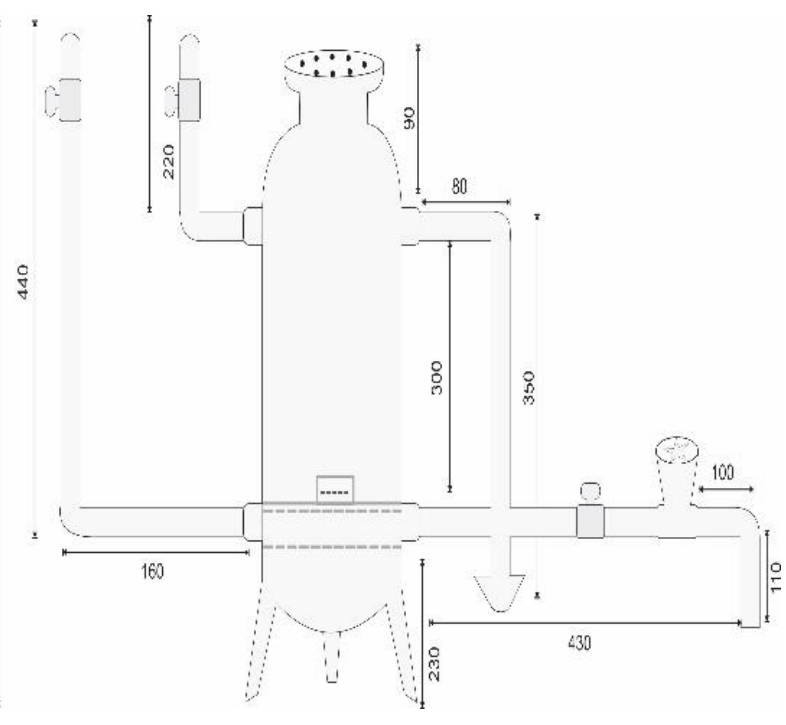

b

Plate 1: Portable household water filter device and its dimensions

The stainless filter component was recharged by filling it with $1000 \mathrm{~g}$ each of $4 \mathrm{~mm}$ gravel, $3 \mathrm{~mm}$ sand and $2 \mathrm{~mm}$ sand while $500 \mathrm{~g}$ each of birm, green sand and activated carbon were also loaded into the filter device. The stainless filter device and its contents were washed by passing excess water through the device to get rid of the powder component in the filter device bed. It was then backwashed for several times for total cleaning of the stainless filter device bed. After recharging and cleaning of the stainless filter component, the cartridge filter component was connected to the stainless filter component. Five litres of water sample, in which two table spoons full of 
chlorine and $50 \mathrm{ml}$ of caustic soda were added; were passed through the stainless filter vessel component and cartridge filter. The resultant sample was collected and taken to the laboratory for analysis This was done for the different samples depending on the variables being investigated. Four variables were employed for data acquisition in this project. These include Aeration, Retention time in the stainless filter component, Retention time in the cartridge filter component and Backwashing of the portable household water filter device

Aeration was achieved by exposing the water sample to the atmosphere to absorb oxygen to aid in breaking the iron (II) $\left(\mathrm{Fe}^{2+}\right)$ to Iron (III) $\left(\mathrm{Fe}^{3+}\right)$. The water samples were first exposed to air for five minutes before they were passed through the portable household water filter device and the resultant treated water samples were collected for laboratory analysis. This was repeated again by exposing the samples for ten minutes, fifteen minutes and twenty minutes. Regarding retention time in the stainless filter component, it was achieved by passing the water samples that were exposed to the atmosphere at different time intervals through the portable household water filter device, (but the outlet valve before the cartridge filter component was locked) at four different time intervals of 5 minutes, 10 minutes, 15 minutes and 20 minutes and the resultant treated water samples were collected, respectively, for further analysis

Retention time in the cartridge filter was achieved the same way it was done in the case of retention time in the stainless filter component. However, in this case, the outlet valve before cartridge filter was opened while the outlet valve after cartridge filter was closed at different time intervals of 5 minutes, 10 minutes, 15 minutes and 20 minutes. The resultant water samples were collected for further analysis. Back washing was carried out for four different cycles of five cycles, ten cycles, fifteen cycles and twenty cycles. After each backwashing, the water samples were passed through and the resultant water samples were collected for further analysis

\section{RESULTS AND DISCUSSION}

The results of the analyses conducted on various water samples, including untreated and treated water samples, obtained during the experimental process, as well as the p-values for using the developed household water filter device are presented in Table 1. Result of the analysis showed changes in some of the parameter as the variables were being manipulated, though some of the parameters did not show much change as the variables were being manipulated. For example, chromium, barium, iron and $\mathrm{pH}$ showed little changes as the variables were being manipulated. The range of values of the differences between treated and untreated water samples as the variables were being manipulated included 0.02-0.03, 0.04-0.05, 0.04-0.12 and 0.3-0.4 mg/L for chromium, barium, iron and $\mathrm{pH}$, respectively. When the aeration was carried out for 5 minutes, 10 minutes, 15 minutes and 20 minutes, the changes shown by these parameters (chromium, barium, iron and $\mathrm{pH}$ ) were insignificant. Similar phenomenon was observed with 5 times backwashing cycles and 5 minutes retention time in the stainless filter and cartridge filter; also with 10 times backwashing cycles and 10 minutes retention time in the reactor and cartridge filter, as well as, 15 times backwashing cycles and 20minutes retention time in the reactor and cartridge filter. When the aeration time and other variables were increased, the changes observed were still not much when compared with the previous values. When the samples were exposed to the atmosphere for 5 minutes aeration, iron contents in the untreated and treated water samples were found to be 0.17 and $.0 .13 \mathrm{mg} / \mathrm{L}$, respectively. They showed some decreasing value as the samples were subjected to $10-, 15$ - and 20-minutes aeration with the average iron contents of the treated water samples being $0.11,0.09$ and $0.07 \mathrm{mg} / \mathrm{L}$, respectively. Water aeration helps to oxidize and remove dissolved metals such as iron; once iron is oxidized from iron (II) which is soluble in water to iron (III) that is less soluble in water, it precipitates out of solution and become particles in the water and can be removed by filtration or floatation [11]

There were, however, important changes in other parameters such as total dissolved solids (TDS), hardness and chloride. The range of values of the differences between treated and untreated water samples as the variables were being manipulated included 125-137, 10-20 and 3-10 mg/L for TDS, hardness and chloride, respectively. For example, the changes were obvious at different manipulated variables of 5 minutes aeration with 5 times backwashing cycles with 5 minutes retention time in the stainless filter and cartridge filter; 10 times backwashing cycles with 10 minutes retention time in the stainless filter and cartridge filter and 15 times backwashing with 20minutes retention time in the stainless filter and cartridge filter.

The initial TDS for the untreated water sample was increased as the retention times of the samples in the reactor and cartridge filter were increased. When it was allowed to stay in the reactor for 5 minutes, the value was different from when it was increased to 10, 15 and 20 minutes. The initial TDS for the original sample was $336 \mathrm{mg} / \mathrm{L}$. 
Table 1: Results of chemical analyses conducted on pipe borne water samples and the p-values for using the developed filter device for the water treatment

\begin{tabular}{|c|c|c|c|c|c|c|c|c|c|c|c|c|}
\hline \multicolumn{4}{|l|}{$\mathrm{S} / \mathrm{N}$} & Barium & Free Chlorine & Chromium & Iron & $\mathrm{pH}$ & $\mathrm{TDS}^{* * * *}$ & Hardness & Chloride & \multirow{3}{*}{$\begin{array}{l}\text { P-values for } \\
\text { using the } \\
\text { device }\end{array}$} \\
\hline \multirow{5}{*}{ A } & \multirow[t]{2}{*}{ Standard } & \multicolumn{2}{|c|}{$\mathrm{NSDWQ}^{*}[9]$} & $0.7 \mathrm{mg} / \mathrm{L}$ & $0.5 \mathrm{mg} / \mathrm{L}$ & $0.05 \mathrm{mg} / \mathrm{L}$ & $0.3 \mathrm{mg} / \mathrm{L}$ & $6.5-8.5$ & $500 \mathrm{mg} / \mathrm{L}$ & $150 \mathrm{mg} / \mathrm{L}$ & $250 \mathrm{mg} / \mathrm{L}$ & \\
\hline & & \multicolumn{2}{|c|}{$\mathrm{WHO}^{* *}[10]$} & $0.7 \mathrm{mg} / \mathrm{L}$ & $0.5 \mathrm{mg} / \mathrm{L}$ & $0.05 \mathrm{mg} / \mathrm{L}$ & $0.3 \mathrm{mg} / \mathrm{L}$ & $6.5-8.5$ & $500 \mathrm{mg} / \mathrm{L}$ & $150 \mathrm{mg} / \mathrm{L}$ & $250 \mathrm{mg} / \mathrm{L}$ & \\
\hline & \multicolumn{2}{|c|}{ Backwashing (cycles) } & 0 & 0.10 & 0.00 & 0.05 & 0.17 & 6.2 & 336 & 20 & 10 & \\
\hline & \multicolumn{2}{|c|}{ Aeration (min) } & 0 & & & & & & & & & \\
\hline & \multicolumn{2}{|c|}{ Retention (min) } & 0 & & & & & & & & & \\
\hline \multirow[t]{3}{*}{ B } & \multicolumn{2}{|c|}{ Backwashing (cycles) } & 5 & 0.06 & 0.00 & 0.02 & 0.13 & 6.5 & 199 & 0 & 0 & 0.254 \\
\hline & \multicolumn{2}{|c|}{ Aeration (min) } & 5 & & & & & & & & & \\
\hline & \multicolumn{2}{|c|}{ Retention (min) } & 5 & & & & & & & & & \\
\hline \multirow[t]{4}{*}{$\mathrm{C}$} & \multicolumn{2}{|c|}{ Backwashing (cycles) } & 5 & 0.06 & 0.00 & 0.02 & 0.12 & 6.5 & 205 & 0 & 0 & 0.251 \\
\hline & Aeration & & 5 & & & & & & & & & \\
\hline & \multirow{2}{*}{\multicolumn{2}{|c|}{ Retention (min) }} & 1 & & & & & & & & & \\
\hline & & & 0 & & & & & & & & & \\
\hline \multirow[t]{6}{*}{$\mathrm{D}$} & \multirow{2}{*}{\multicolumn{2}{|c|}{ Backwashing (cycles) }} & 1 & 0.06 & 0.00 & 0.03 & 0.11 & 6.5 & 201 & 5 & 0 & 0.267 \\
\hline & & & 0 & & & & & & & & & \\
\hline & \multirow{2}{*}{\multicolumn{2}{|c|}{ Aeration (min) }} & 1 & & & & & & & & & \\
\hline & & & 0 & & & & & & & & & \\
\hline & \multirow{2}{*}{\multicolumn{2}{|c|}{ Retention(min) }} & 1 & & & & & & & & & \\
\hline & & & 0 & & & & & & & & & \\
\hline \multirow[t]{5}{*}{$\mathrm{E}$} & \multirow{2}{*}{\multicolumn{2}{|c|}{ Backwashing (cycles) }} & 1 & 0.06 & 0.00 & 0.02 & 0.10 & 6.5 & 202 & 1 & 2 & 0.261 \\
\hline & & & 0 & & & & & & & & & \\
\hline & \multirow{2}{*}{\multicolumn{2}{|c|}{ Aeration (min) }} & 1 & & & & & & & & & \\
\hline & & & 0 & & & & & & & & & \\
\hline & \multicolumn{2}{|c|}{ Retention (min) } & 5 & & & & & & & & & \\
\hline \multirow[t]{6}{*}{$\mathrm{F}$} & \multirow{2}{*}{\multicolumn{2}{|c|}{ Backwashing (cycles) }} & 1 & 0.06 & 0.00 & 0.03 & 0.10 & 6.5 & 205 & 5 & 0.05 & 0.265 \\
\hline & & & 5 & & & & & & & & & \\
\hline & \multirow{2}{*}{\multicolumn{2}{|c|}{ Aeration (min) }} & 1 & & & & & & & & & \\
\hline & & & 5 & & & & & & & & & \\
\hline & \multirow{2}{*}{\multicolumn{2}{|c|}{ Retention (min) }} & 1 & & & & & & & & & \\
\hline & & & 5 & & & & & & & & & \\
\hline
\end{tabular}


Table 1 (cont.)

\begin{tabular}{|c|c|c|c|c|c|c|c|c|c|c|c|c|}
\hline \multirow[t]{3}{*}{$\mathrm{S} / \mathrm{N}$} & & & & Barium & $\begin{array}{l}\text { Free } \\
\text { Chlorine }\end{array}$ & Chromium & Iron & pH & TDS $^{* * * *}$ & Hardness & Chloride & \multirow{3}{*}{$\begin{array}{l}\text { P-values for } \\
\text { using the } \\
\text { device }\end{array}$} \\
\hline & \multirow[t]{2}{*}{ Standard } & \multicolumn{2}{|c|}{ NSDWQ $^{*}[9]$} & $0.7 \mathrm{mg} / \mathrm{L}$ & $0.5 \mathrm{mg} / \mathrm{L}$ & $0.05 \mathrm{mg} / \mathrm{L}$ & $0.3 \mathrm{mg} / \mathrm{L}$ & $6.5-8.5$ & $500 \mathrm{mg} / \mathrm{L}$ & $150 \mathrm{mg} / \mathrm{L}$ & $250 \mathrm{mg} / \mathrm{L}$ & \\
\hline & & \multicolumn{2}{|c|}{$\mathrm{WHO}^{* *}[10]$} & $0.7 \mathrm{mg} / \mathrm{L}$ & $0.5 \mathrm{mg} / \mathrm{L}$ & $0.05 \mathrm{mg} / \mathrm{L}$ & $0.3 \mathrm{mg} / \mathrm{L}$ & $6.5-8.5$ & $500 \mathrm{mg} / \mathrm{L}$ & $150 \mathrm{mg} / \mathrm{L}$ & $250 \mathrm{mg} / \mathrm{L}$ & \\
\hline \multirow[t]{5}{*}{ G } & \multirow{2}{*}{\multicolumn{2}{|c|}{ Backwashing (cycles) }} & 1 & 0.06 & 0.01 & 0.02 & 0.09 & 6.6 & 211 & 3 & 7 & 0.279 \\
\hline & & & 5 & & & & & & & & & \\
\hline & \multirow{2}{*}{\multicolumn{2}{|c|}{ Aeration (min) }} & 1 & & & & & & & & & \\
\hline & & & 5 & & & & & & & & & \\
\hline & \multicolumn{2}{|c|}{ Retention (min) } & 0 & & & & & & & & & \\
\hline \multirow[t]{6}{*}{$\mathrm{H}$} & \multirow{2}{*}{\multicolumn{2}{|c|}{ Backwashing (min) }} & 2 & 0.05 & 0.00 & 0.02 & 0.09 & 6.5 & 210 & 6 & 0.05 & 0.265 \\
\hline & & & 0 & & & & & & & & & \\
\hline & \multirow{2}{*}{\multicolumn{2}{|c|}{ Aeration (min) }} & 2 & & & & & & & & & \\
\hline & & & 0 & & & & & & & & & \\
\hline & \multirow{2}{*}{\multicolumn{2}{|c|}{ Retention (min) }} & 2 & & & & & & & & & \\
\hline & & & 0 & & & & & & & & & \\
\hline \multirow[t]{4}{*}{ I } & \multirow{2}{*}{\multicolumn{2}{|c|}{ Backwashing (cycles) }} & 2 & 0.06 & 0.00 & 0.02 & 0.05 & 6.5 & 201 & 10 & 5 & 0.298 \\
\hline & & & 0 & & & & & & & & & \\
\hline & \multicolumn{2}{|c|}{ Aeration (min) } & 0 & & & & & & & & & \\
\hline & \multicolumn{2}{|c|}{ Retention (min) } & 5 & & & & & & & & & \\
\hline
\end{tabular}

"NSDWQ - Nigerian Standard for Drinking water quality; $\quad$ WHO $^{* *}$-World Health Organization;

${ }^{* * *}$ TDS - total dissolved solids 
For 5, 10, 15, and 20 minutes of retention time in the reactor, the average values were 201, 206, 205 and 210, respectively. Regarding hardness, the values increased as the variables being manipulated were increased. For 5, 10, 15 and 20 minutes of retention time; the average values of hardness were 4, 3, 5, and 6 , respectively, as against the hardness value of the untreated water sample which was 20 . The result of microbiological and physical analyses conducted on the pipe borne water samples during the experimental study is presented in Table 2 . The microorganisms found in the untreated pipe borne water included coliform, yeast and molds with concentration values of 15 $\mathrm{CFU} / 100 \mathrm{~mL}, 3 \mathrm{CFU} / \mathrm{mL}$ and $5 \mathrm{CFU} / \mathrm{mL}$, respectively. The concentration values of coliforms, yeast and molds in the treated water samples were $0 \mathrm{CFU} / 100 \mathrm{~mL}, 2 \mathrm{CFU} / \mathrm{mL}$ and $1 \mathrm{CFU} / \mathrm{mL}$, respectively. It was observed in Table 1 that despite the application of chlorine for the disinfection of microorganisms in the pipe borne water, no trace of chlorine residual was observed in both untreated and treated pipe borne water samples. Comparing the values of microorganism in the untreated pipe borne water with the maximum acceptable limits of WHO and NSDWQ, it is obvious that the treatment of the water with the developed filter device was necessary to prevent water related diseases in people drinking the water. Regarding colour, taste and odour of the untreated and treated pipe borne water samples, they were observed to meet the maximum acceptable limits of WHO and NSDWQ (Table 2)

Statistical analysis was performed to determine the necessity of using the developed portable household water filter device in the treatment of the pipe borne water under the various conditions of aeration periods, backwashing cycles and retention times. The Minitab paired t-test was used to analyse if there were significant mean difference between the values of the untreated and treated pipe borne water parameters. As given in Table 1, the p-values when considering the parameters of the untreated and treated pipe borne water samples under the various experimental conditions, ranged from 0.251 to 0.298 . As the $p$-values were greater than $\alpha$-level $=0.05$, it could be concluded that there was no statistical difference between the values of the parameters of the untreated and treated pipe borne water samples under the various conditions investigated. This does not mean that the developed portable household water filter device is not relevant in the quality improvement of pipe borne water. Even under the investigated experimental conditions, the water parameter values of the untreated and treated pipe borne water samples were not the same, instead the parameters of the treated water samples had improved quality level. Meanwhile, the application of the filter device may be statistically significant under other experimental conditions of aeration period, backwashing cycles and retention times. Therefore, effort will be made in future research to try other means of improving water qualities using the same filter device.

Table 2: Results of microbiological and physical analyses conducted on pipe borne water samples during the experimental study

\begin{tabular}{|c|c|c|c|c|c|c|c|}
\hline \multicolumn{2}{|c|}{ Water Type } & $\begin{array}{l}\text { Total Coliform } \\
\text { (CFU/100mL) }\end{array}$ & $\begin{array}{l}\text { Yeast } \\
(\mathrm{CFU} / \mathrm{mL})\end{array}$ & $\begin{array}{l}\text { Mold } \\
\text { (CFU/mL) }\end{array}$ & Colour & Taste & Odour \\
\hline \multirow[t]{2}{*}{ Standard } & $\mathrm{WHO}^{*}$ & 0 & 5 & 5 & $15 \mathrm{TCU}$ & Unobjectionable & Unobjectionable \\
\hline & $\mathrm{NSDWQ}^{* *}$ & 0 & 5 & 5 & $15 \mathrm{TCU}$ & Unobjectionable & Unobjectionable \\
\hline \multicolumn{2}{|c|}{ Untreated pipe borne water } & 15 & 3 & 5 & Colourless & Unobjectionable & Odourless \\
\hline \multicolumn{2}{|c|}{ Treated Pipe borne water } & 0 & 2 & 1 & Colourless & Unobjectionable & Odourless \\
\hline
\end{tabular}

"NSDWQ - Nigerian Standard for Drinking water quality

**WHO-World Health Organization

\section{CONCLUSION}

This paper has described the development and application of portable household water filter device for improving the quality of pipe borne water. Although the statistical analysis of the results indicated the non-significance of using the developed water device under the various experimental conditions studied; the comparison of the physicochemical and microbiological parameters of the untreated and treated pipe borne water samples indicated that there was improvement in the quality of the treated pipe borne water when compared to the untreated water. To justify the significance of using the portable household water filter device, other experimental conditions will be investigated in future studies. The importance of usage of the household water filter device cannot be understated as it will enable people to be less dependent on the government for the provision of healthy water. Besides, application of the device will develop the capacity of people regarding the treatment of water for safe consumption. The study therefore 
recommended that individuals should endeavor to have this or similar house hold water treatment vessel for purification of their consumable water.

\section{ACKNOWLEDGEMENT}

The authors are grateful for the support from Lagos State University management, as well as, the assistance provided by Mrs. Itohan of Golden Pasta Agbara QA/QC department who helped to carry out laboratory analyses on the various water samples.

\section{REFERENCE}

1. T. Oki, S. Kanae, “Global hydrological cycles and world water resources”. Science, Vol 313, No 5790, 2006, 1068-1072.

2. C.LChan, M.K.Zalifah, A.S. Norrakiah, "Microbiological and physiochemical quality of drinking water". Malaysian J Analyt Sci, Vol 11, No 2, 2007,414-420.

3. N.M. Abdel-Moety,F.A. Al-Fassi,M.A. Ali, "Health aspects of virological water quality: an overview review”. J. Appl Sci Res, Vol 4, No 10, 2008, 205-215.

4. J.K. Tumwine, J. Thompson, M. Katua-Katua, M.Mujwajuzi, N. Johnstone, I.Porras, "Diarrhoea and effects of different water sources, sanitation and hygiene behaviour in East Africa".Trop Med Int Health, Vol 7, No 9, 2002, 750-756.

5. N.H.Mthombeni, L. Mpenyana-Monyatsi, M.S. Onyango, M.N.B.. Momba, "Breakthrough Analysis for Water Disinfection Using Silver Nanoparticles Coated Resin Beads in Fixed bed Column". Journal of Hazardous Materials, Vol 217,-218, 2012, 133-140.

6. E.I. Ekwue, V. Dhanraj, R.A. Bircg, “A Simple Portable Potable Water Treatment Plant in Rural Areas”. The Journal of the Association of Professional Engineers of Trinidad and Tobago, Vol 41, No 1, 2013, 29-34

7. M. El-harbawi, A.B. Sabidi, E.B. Kamarudin, A.B. Abd-Hamid, S.B. Harun, A.B. Nazlan, C.X. Yi, Design of a portable dual purposes water filter system". Journal of Engineering Science and Technology, Vol 5, No 2, 2010, 165 - 175.

8. Y. Madrid, Z.P. Zayas, "Water sampling: traditional methods and new approaches in water sampling strategy". Trends in Analytical Chemistry, Vol 26, No 4, 2007, 293-299

9. Nigerian Standard for Drinking water quality (NSDWQ), Nigeria, Ministry of Water Resources, Nigeria, pp. 1-2. NIS 554: 2007. Approved by SON Governing Council

10. World Health Organization (1997) Guidelines for Drinking water Quality: Surveillance and control of community supplies. Ceneva: World Health Organization 2nd Edition. Vol. 3

11. S.J. Kulkarni,"Review on aeration: studies and investigations across various applications". International Journal of Research and Review, Vol 4, No 4, 2017, 57-63. 